\title{
Effect of particle size of blueberry pomace powder on its properties
}

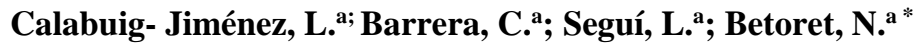 \\ ${ }^{a}$ Institute of Food Engineering for Development. Universitat Politècnica de València. Camino de Vera \\ s/n, 46022, Valencia, Spain. \\ *E-mail of the corresponding author: noebeval@tal.upv.es
}

\begin{abstract}
Producing dried powders from blueberry pomace allows to reduce its environmental impact and gives value to this waste material. This work aims to evaluate the effect of particle size (fine or coarse) of blueberry pomace dried at $70{ }^{\circ} \mathrm{C}$ on its fibre content and main physicochemical properties, including antiradical capacity, total phenols and anthocyanins content, hydration and emulsifying properties. The effect of storage on antioxidant properties was also evaluated. Results showed a significant effect of particle size on fibre content and consequently, on water retention, holding and emulsifying capacity of the powder. Neither phenols nor anthocyanins were affected by particle size or storage time.
\end{abstract}

Keywords: blueberry pomace, powders, fibre, antioxidant properties. 


\section{Introduction}

Fruit and vegetables industrialization produces a huge amount of waste with negative impact on the environment and expensive management [1]. Most of this waste is used as animal feed or as fertilizers, both having low economic value. In an environmentally friendly way, it would be very interesting to use agro-food industry waste and by-products as a source of edible ingredients, thus increasing added value of the waste materials. Fruit powders have become an emerging way of consuming fruit and vegetables and it has attracted a growing interest in recent years [2], according to their broad applications in food formulation as colorant, flavoring ingredient or as natural preservatives. Fruit by-products also contain high amounst of health-promoting compounds such as, fibre, proteins, vitamins and minerals [1]. Blueberries has anti-inflammatory properties and has been reported to prevent several diseases. This health benefits have been attributed to their content in various phenolic compounds such as anthocyanins and other flavonoids [3]. Due to the fruit seasonal availability and a recent increase in the production, industrialization of the blueberries into juice, dried fruit and powders has increased in the last years. Fiber and phenolic constituents have higher concentration in blueberry pomace, a by-product of juice processing, than in the fruit itself [1]; in addition, beneficial effects of these by-products on metabolomic alterations have been reported [4]. Fiber content of blueberry pomace may offer functional properties associated with water retention and emulsifiying capacity. Among the processing methods that could be applied to estabilized bluberry pomace, drying an further powdering could be a good way to increase the shelf life of the product [5]. The aim of this research was to evaluate physicochemical properties, including antioxidant properties and other technological properties, of a blueberry pomace powder obtained by air driying at $70{ }^{\circ} \mathrm{C}$ and grinding at two different intensities. Changes on antioxidant properties after 20 weeks of storage were also determined.

\section{Materials and Methods}

\subsection{Blueberry pomace}

Frozen blueberries (V. corymbosum var. duke) were supplied by Samanes S.L (Navarra, Spain) and processed as [7]. Separated blueberry pomace (P) was air dried at $70{ }^{\circ} \mathrm{C}$ (POLEKO, Controltecnica, S.L., Madrid) until reaching a water activity below 0.3 . Dried pomace (DP) was grinded at $10,000 \mathrm{rpm}$ (Thermomix ${ }^{\circledR}$, Vorwerk, Spain) for $10 \mathrm{~s}$ to obtain a coarse powder (CP) and for 2 min at $30 \mathrm{~s}$ intervals to obtain a fine powder (FP). Powders were stored in opaque glass jars under controlled relative humidity of $24 \%$ at $25 \pm 1{ }^{\circ} \mathrm{C}$ until analysis. Antioxidants stability of powders during 20 weeks of storage were evaluated.

\subsection{Physicochemical properties}

Water activity was measured with a dewpoint hygrometer (Aqualab 4TE; Decagon devices Inc., Pullman WA, USA). Moisture was obtained by method described by [7]. Total soluble solids content of samples $\left(\mathrm{x}_{\mathrm{ss}}\right)$ were determined by refractometry, measuring Brix degrees of a solution 1:10 (w/v), and transformed into $\mathrm{x}_{\mathrm{ss}}$ as appropriate. Specific volume of powders was obtained by measuring the volume of a sample in a $10 \mathrm{~mL}$ test tube. All determinations were performed in triplicate. 
Particle size distribution of the powders was determined by diffraction laser (Mastersizer 2000, Malvern Instruments, UK) with air as dispersant at 2.5 bar (dry method) or water (wet method); refraction indexes were 1.52 for the sample and 1.33 for the dispersed phase. Characterization was made in terms of $\mathrm{D}[4,3], \mathrm{D}[3,2]$, and $\mathrm{d}_{10}, \mathrm{~d}_{50}$ and $\mathrm{d}_{90}$. Provided results are the average of five replicates. CIEL*a*b* coordinates, hue and chrome were measured with a spectrocolorimeter (MINOLTA model CM-1000R). Values provided are the average of triplicates. Fibre content, Neutral Detergent Fibre (NDF), Acid Detergent Fibre (ADF), and Lignin Detergent Fibre (LDF) were obtained as [8]; these allowed obtaining the amount of hemicellulose (soluble fibre), cellulose, lignin (non-soluble fibre) and total fibre. Fiber determinations were performed in duplicate and results were given in percentage of dry basis (db).

An $80 \%$ methanol:water solution was used to extract the antioxidant compounds of the fresh pomace (1:20 w/v solution) and the dried powders (1:100 w/v solution). After $1 \mathrm{~h}$ of stirring, the mixture was centrifuged at $10,000 \mathrm{rpm}$ for $5 \mathrm{~min}$. Total phenol content of samples was obtained following the Folin-Ciocalteau method slightly modified [9]. Results were given in mg of Gallic Acid Equivalents (GAE) per $100 \mathrm{~g}$ of sample (db). Monomeric anthocyanin content was obtained by the $\mathrm{pH}$ differential spectrophotometric method as in [10]. Absorbance (Helios Zeta UV/Vis, Thermo scientific, UK) was measured at $510 \mathrm{~nm}$ and $700 \mathrm{~nm}$ at $\mathrm{pH} 1.0$ and 4.5. In order to obtain the monomeric anthocyanin content equations (1) and (2) were applied, where: Abs 510 is the absorbance at $510 \mathrm{~nm} \mathrm{Abs} 700$ is the absorbance at $700 \mathrm{~nm}, \mathrm{Mw}$ : molecular weight of glucosid-3-cyanidin $(449.2 \mathrm{~g} / \mathrm{mol})$, f: dilution factor, $\varepsilon$ : molar extinction coefficient $(26,9 \mathrm{~L} / \mathrm{mol} \cdot \mathrm{cm})$. Results were given as mg of cyanidin-3-Oglucoside equivalents per $100 \mathrm{~g}$ of sample (db). The antioxidant activity (AA) was measured with DPPH and ABTS methods described in [9]. Presented results were expressed in mg of Equivalent Trolox (ET) per g of sample sample (db). All antioxidant determinations were performed in triplicate.

$$
\begin{aligned}
& \mathrm{ABS}=\left(\mathrm{Abs}_{510}-\mathrm{Abs}_{700}\right)_{\mathrm{pH} \mathrm{1.0}}-\left(\mathrm{Abs}_{510}-\mathrm{Abs}_{700}\right)_{\mathrm{pH} 4.5} \\
& \text { Total monomeric anthocyanin }=\frac{\mathrm{ABS} \cdot \mathrm{Mw} \cdot \mathrm{f} \cdot 1000}{\varepsilon \cdot \mathrm{l}}
\end{aligned}
$$

Hygroscopicity was measured according as the water gained by the powders in a hermetic container with a saturated solution of $\mathrm{Na}_{2} \mathrm{SO}_{4}(81 \% \mathrm{RH})$ during one week(g/100 g dry solids). Solubility was determined as the ratio of soluble solids:total solids. Wettability was determined as a result of the time in which $2 \mathrm{~g}$ of samples takes to get completely wet in water. The swelling capacity (SC) was obtained from the ratio between the volume of the sample after $18 \mathrm{~h}$ at $25^{\circ} \mathrm{C}$ and the initial weight. Results are given in $\mathrm{mL} / \mathrm{g}$ as the average and standard deviation of thee replicates.

Water holding capacity (WHC) was obtained as the water contained in the hydrated residue per unit of dry matter. It was obtained by means of equation 3 , where HR is the weight of the hydrated powder ( $\sim \mathrm{g}$ of powder hydrated during 18 hours at $25^{\circ} \mathrm{C}$ ), and DR the weight of the freeze dried sample (DR). Water retention capacity (WRC) was obtained as follows: sample was weighed in a conical tube and hydrated with water during $18 \mathrm{~h}$ at $25^{\circ} \mathrm{C}$. Then, 
the tube was centrifuged at $514 \mathrm{x}$ g during $30 \mathrm{~min}$ and sample weighed $(\mathrm{R}+\mathrm{W})$. After, ther residue was freeze dried and weighed $(\mathrm{R})$. WRC was calculated as the ratio between the W and the R. Results correspond to the average of three replicates.

$$
\mathrm{WHC}=\frac{\mathrm{HR}-\mathrm{DR}}{\mathrm{DR}}
$$

Oil holding capacity (OHC, in g of oil per g of powder) was obtained following the method described by [11]. Powdered samples were mixed with sunflower oil and kept overnight at room temperature. Samples were then centrifuged at $1,500 \mathrm{x}$ g during $5 \mathrm{~min}$, the supernatant was discarded and weight of pellet obtained. Results are the average of three replicates. Emulsifying activity (EA) was obtained as described by [12]. Samples were diluted in water $(2 \% \mathrm{w} / \mathrm{v})$ and mixed with sunflower oil in a vortex at 2,400 rpm for $5 \mathrm{~min}$. Then, the mixture was centrifuged at $12,857 \mathrm{x}$ g for $5 \mathrm{~min}$ and the emulsion volume was obtained according to equation 6, in which VEL refers to the volume of the emulsified layer $(\mathrm{mL})$ and $V$ to the total volume of fluid (mL). Emulsion stability (ES) was evaluated using the method described by [12]. The emulstion prepared to obtain EA, was heated up to $80^{\circ} \mathrm{C}$ during $30 \mathrm{~min}$. When tempered again at room temperature, it was centrifuged at $514 \times$ g during 5 min. ES was obtained as equation 7 , where $\mathrm{V}_{\mathrm{REL}}$ is the volume of the emulsion layer ( $\mathrm{mL}$ ) and $\mathrm{V}$ is the total volume of fluid (mL).

$$
\begin{aligned}
& \% E A=\frac{V E L}{V} \cdot 100 \\
& \% E S=\frac{V_{\text {REL }}}{V} \cdot 100
\end{aligned}
$$

\section{Results and discussion}

Water activity $\left(\mathrm{a}_{\mathrm{w}}\right)$, moisture content $\left(\mathrm{x}_{\mathrm{w}}\right)$ and total soluble solids $\left(\mathrm{x}_{\mathrm{ss}}\right)$ of fresh pomace $(\mathrm{P})$, dried pomace (DP) and grinded dried pomace to a coarse powder (CP) or to a fine powder (FP) are shown in table 1 .

Table 1. Water activity, moisture $\left(g_{w} / g\right)$ and $x_{s s}\left(g_{\text {soluble solids }} / g\right)$ of fresh and dried blueberry pomace. Mean \pm standard deviation of three replicates.

\begin{tabular}{cccc}
\hline & $\mathbf{a}_{\mathbf{w}}$ & $\mathbf{X}_{\mathbf{w}}$ & $\mathbf{X}_{\text {ss }}$ \\
\hline P & $0.989 \pm 0.003^{\mathrm{c}}$ & $0.722 \pm 0.003^{\mathrm{b}}$ & $0.079 \pm 0.002^{\mathrm{a}}$ \\
$\mathrm{DP}$ & $0.189 \pm 0.004^{\mathrm{a}}$ & $0.0173 \pm 0.0015^{\mathrm{a}}$ & $0.28 \pm 0.011^{\mathrm{b}}$ \\
$\mathrm{CP}$ & $0.236 \pm 0.004^{\mathrm{b}}$ & $0.0170 \pm 0.0019^{\mathrm{a}}$ & $0.35 \pm 0.011^{\mathrm{b}}$ \\
FP & $0.20 \pm 0.06^{\mathrm{a}} \mathrm{b}$ & $0.019 \pm 0.0006^{\mathrm{a}}$ & $0.46 \pm 0.012^{\mathrm{c}}$ \\
\hline
\end{tabular}

Values with different superscript letters in the same column are significantly different $(\mathrm{p}<0.05)$.

As expected, dried pomace resulted in a much more stable and rich in soluble solids product than wet pomace. After grinding, both the water activity and the soluble solids content increased significantly, thus indicating that the reduction in the particle size promotes the water ability to conduct deterioration reactions and the solutes ability to dissolve. Indeed, the 
finer the powder, the greater the breakdown of long polysaccharides chains and the release of shorter and more soluble ones. As a result, not only the soluble solids content of FP was higher than that of $\mathrm{CP}$, but also the fiber content of FP was significantly lower than that of CP (table 2). It is worth noting that the fiber content of any of the powders is over $30 \%$ and that insoluble fiber represents around $68 \%$ of total fiber, since other properties such as the hydration and emulsifying properties of the powders will depend on them [13].

Table 2. Content (\%) of cellulose, hemicellulose, lignin, insoluble fibre and total fibre of coarse (CP) and fine (FP) powders. Mean \pm standard deviation of two replicates.

\begin{tabular}{cccccc}
\hline & Cellulose & Hemicellulose & Lignin & $\begin{array}{c}\text { Insoluble } \\
\text { fiber }\end{array}$ & Total fiber \\
\hline CP & $18.0 \pm 0.4^{\mathrm{b}}$ & $12.847 \pm 0.018^{\mathrm{b}}$ & $7.6 \pm 0.2^{\mathrm{b}}$ & $25.6 \pm 0.8^{\mathrm{b}}$ & $38.5 \pm 0.8^{\mathrm{b}}$ \\
FP & $16.69 \pm 0.14^{\mathrm{a}}$ & $10.444 \pm 0.003^{\mathrm{a}}$ & $6.6 \pm 0.2^{\mathrm{a}}$ & $23.24 \pm 0.06^{\mathrm{a}}$ & $33.69 \pm 0.06^{\mathrm{a}}$ \\
\hline
\end{tabular}

Values with different superscript letters in the same column are significantly different $(\mathrm{p}<0.05)$.

Grinding intensity of the powders, for the powder and for the powder in solution, the average size of particles in FP was significantly lower than that in CP (table 3). This will affect hydration related properties of the powders.

Table 3. Results of $D[4,3], D[3,2]$, and $d_{10}, d_{50}$ and $d_{90}$ of particle size distribution of coarse (CP) and fine powder (FP). Mean \pm standard deviation of six replicates.

\begin{tabular}{ccccccc}
\hline & & $\mathbf{D}[\mathbf{4 , 3}]$ & $\mathbf{D}[\mathbf{3 , 2}]$ & $\mathbf{d}_{\mathbf{1 0}}$ & $\mathbf{d}_{\mathbf{5 0}}$ & $\mathbf{d}_{\mathbf{9 0}}$ \\
\hline Dry & CP & $659 \pm 10^{\mathrm{d}}$ & $239 \pm 8^{\mathrm{d}}$ & $129 \pm 5^{\mathrm{d}}$ & $606 \pm 10^{\mathrm{c}}$ & $1247 \pm 17^{\mathrm{d}}$ \\
method & FP & $211 \pm 2^{\mathrm{a}}$ & $81 \pm 4^{\mathrm{a}}$ & $36 \pm 1^{\mathrm{a}}$ & $170,1 \pm 0,7^{\mathrm{a}}$ & $446 \pm 7^{\mathrm{a}}$ \\
\hline Wet & CP & $437 \pm 106^{\mathrm{c}}$ & $177 \pm 32^{\mathrm{c}}$ & $71 \pm 13^{\mathrm{c}}$ & $398 \pm 79^{\mathrm{b}}$ & $873 \pm 236^{\mathrm{c}}$ \\
method & FP & $293 \pm 66^{\mathrm{b}}$ & $100 \pm 48^{\mathrm{b}}$ & $52 \pm 6^{\mathrm{b}}$ & $209 \pm 51^{\mathrm{a}}$ & $680 \pm 206^{\mathrm{b}}$ \\
\hline
\end{tabular}

Values with different superscript letters in the same column are significantly different $(\mathrm{p}<0.05)$.

Specific volume, solubility, hydration and water retention and emulsifying properties of coarse and fine powders are collected in table 4.

Table 4. Results of specific volume, solubility, hydration and water retention properties and emulsifying properties for the powders. Mean \pm standard deviation of three replicates.

\begin{tabular}{lcc}
\hline & CP & FP \\
\hline Specific volume (mL/g) & $9.60 \pm 0.12^{\mathrm{b}}$ & $7.57 \pm 0.06^{\mathrm{a}}$ \\
Solubility (\%) & $31.6 \pm 1.5^{\mathrm{a}}$ & $33.1 \pm 0.7^{\mathrm{a}}$ \\
Higroscopicity (\%) & $61 \pm 3^{\mathrm{a}}$ & $62.7 \pm 1.8^{\mathrm{a}}$ \\
Wettability (s) & $175 \pm 21^{\mathrm{b}}$ & $77 \pm 6^{\mathrm{a}}$ \\
Swelling capacity (SC, mL/g) & $2.88 \pm 0.13^{\mathrm{b}}$ & $2.56 \pm 0.06^{\mathrm{a}}$ \\
Water holding capacity (WHC) (g/g) & $5.1 \pm 0.2^{\mathrm{b}}$ & $4.63 \pm 0.16^{\mathrm{a}}$ \\
Water retention capacity (WRC) (g/g) & $3.4 \pm 0.3^{\mathrm{a}}$ & $3.08 \pm 0.18^{\mathrm{a}}$ \\
Oil holding capacity (OHC) (g/g) & $2.7 \pm 0.6^{\mathrm{a}}$ & $2.9 \pm 0.5^{\mathrm{a}}$ \\
Emulsifying activity (EA, \%) & $0.4 \pm 0.1^{\mathrm{a}}$ & $0.53 \pm 0.12^{\mathrm{a}}$ \\
Emulsion stability (ES, \%) & $3 \pm 2^{\mathrm{b}}$ & $1.5 \pm 0.7^{\mathrm{a}}$ \\
\hline
\end{tabular}

Values with different superscript letters in the same row are significantly different $(\mathrm{p}<0.05)$. 
Regardless of the particle size, solubility of blueberry pomace powders was quite low, but similar to that reported for asparagus fiber [14]. The high fiber content, especially of the insoluble type, would be the main cause of this. In the same way, hygroscopicity was of the order of that obtained by [15]. Among the properties here analyzed, only the specific volume, the wettability, the SC, the WHC and the ES were significantly affected by the particle size of the powder, with higher values in CP samples than in FP ones. This could be due to the higher porosity of the powders of bigger size particles and, consequently, to the higher amount of air retained in their structure [16]. As for wettability, the lower density of CP involved that this sample remained more time on the water surface, thus increasing the time to get completely wet. Although emulsifying properties are reported to be affected by the type, the size, the shape the superficial area and the chemical composition of different fiber particles [17], these took very similar values in the two powders analyzed. OHC, EA and ES of blueberry pomace powders were similar to that of peach, and apple fibers [18]. Color of powders (table 5) were affected by both the drying and the grinding steps. Drying significantly increased all the color coordinates, including chrome and hue. Grinding effect on color was only evident for FP, that resulted slightly less red and yellow than the CP. In any case, differences in the color of the samples were imperceptible to the human eye.

Table 5. CIEL*a*b* coordinate, chroma and hue of fresh pomace (P), dried pomace (DP), coarse (CP) and fine (FP) powder. Mean \pm standard deviation of two replicates.

\begin{tabular}{cccccc}
\hline & $\mathbf{L}^{*}$ & $\mathbf{a}^{*}$ & $\mathbf{b}^{*}$ & $\mathbf{C}$ & $\mathbf{h}$ \\
\hline $\mathrm{P}$ & $26.50 \pm 1.0^{\mathrm{a}}$ & $3.0 \pm 0.3^{\mathrm{a}}$ & $0.19 \pm 0.3^{\mathrm{a}}$ & $3.0 \pm 0.3^{\mathrm{a}}$ & $3.7 \pm 0.7^{\mathrm{a}}$ \\
$\mathrm{DP}$ & $37.5 \pm 0.3^{\mathrm{b}}$ & $3.80 \pm 0.10^{\mathrm{c}}$ & $0.65 \pm 0.09^{\mathrm{b}}$ & $3.86 \pm 0.08^{\mathrm{c}}$ & $9.8 \pm 1.5^{\mathrm{b}}$ \\
$\mathrm{CP}$ & $37.52 \pm 0.2^{\mathrm{b}}$ & $3.8 \pm 0.08^{\mathrm{c}}$ & $0.68 \pm 0.08^{\mathrm{b}}$ & $3.9 \pm 0.07^{\mathrm{c}}$ & $10.1 \pm 1.3^{\mathrm{b}}$ \\
FP & $37.08 \pm 0.10^{\mathrm{b}}$ & $3.37 \pm 0.05^{\mathrm{b}}$ & $0.12 \pm 0.05^{\mathrm{a}}$ & $3.37 \pm 0.5^{\mathrm{b}}$ & $2.0 \pm 0.9^{\mathrm{a}}$ \\
\hline
\end{tabular}

Values with different superscript letters in the same column are significantly different $(\mathrm{p}<0.05)$.

Antioxidant properties of different samples are shown in table 6. As it can be observed, total phenols content (TP) reached higher values in P and DP than in grinded samples. Within the powders, the higher values obtained for FP could be due to a greater extractability of such compunds as the particle size decreased [13]. As regards the monomeric anthocyanidins content (MA), their content decreased significantly after the drying step because they are sensitive to both temperature and oxidation [19]. Grinding only affected MA content of FP due to its higher surface/volume ratio and its subsequent higher exposure to oxygen. In agreement with these results, the antioxidant activity (AA) of blueberry pomace measured by both DPPH and ABTS methods was significantly reduced due to drying and further grinding.

Table 6. TP content (mg GAE/100 g db), MA (mg glucosid-3-cyanidin/100 g db), AA with DPPH and ABTS methods ( $\mathrm{mg} T E / \mathrm{g} \mathrm{db})$. Mean \pm standard deviation of three replicates.

\begin{tabular}{ccccc}
\hline & TP & MA & AA- DPPH & AA- ABTS \\
\hline P & $4.4 \pm 0.2^{\mathrm{c}}$ & $74.5 \pm 0.4^{\mathrm{c}}$ & $145.7 \pm 0.6^{\mathrm{c}}$ & $87.3 \pm 0.4^{\mathrm{c}}$ \\
DP & $4.48 \pm 0.12^{\mathrm{c}}$ & $48.9 \pm 0.7^{\mathrm{b}}$ & $101.1 \pm 0.7^{\mathrm{b}}$ & $60.0 \pm 1.6^{\mathrm{b}}$ \\
CP & $3.02 \pm 0.12^{\mathrm{a}}$ & $49.0 \pm 0.9^{\mathrm{b}}$ & $100.8 \pm 0.7^{\mathrm{b}}$ & $55 \pm 3^{\mathrm{a}}$ \\
FP & $3.36 \pm 0.10^{\mathrm{b}}$ & $31 \pm 4^{\mathrm{a}}$ & $83.8 \pm 1.5^{\mathrm{a}}$ & $57 \pm 2^{\mathrm{a}, \mathrm{b}}$ \\
\hline
\end{tabular}

Values with different superscript letters in the same column are significantly different $(\mathrm{p}<0.05)$. 
Antioxidant properties of the powders were measured again after 20 weeks of storage under controlled conditions. Differences between initial and final values of all compounds are shown in table 7. In general terms, the antioxidant properties of the powders remained quite stable during storage, regardless of the powder particle size. Only the antioxidant activity of the coarse powder measured by DPPH was significantly lower after storage.

Table 7. TP (mg GAE/100 g db), MA (mg glucosid-3-cyanidin/100 g db)content and AA with

$D P P H$ and ABTS methods ( $\mathrm{mg}$ TE/g db) reduction after 20 weeks of storage. Mean \pm standard deviation of three replicates.

\begin{tabular}{ccccc}
\hline & TP & MA & AA- DPPH & AA- ABTS \\
\hline CP & $-0.18 \pm 0.13^{\mathrm{a}}$ & $0 \pm 3^{\mathrm{a}}$ & $18.4 \pm 1.1^{\mathrm{b}}$ & $-1 \pm 2^{\mathrm{a}}$ \\
FP & $0.35 \pm 0.18^{\mathrm{a}}$ & $-4 \pm 2^{\mathrm{a}}$ & $8.2 \pm 1.1^{\mathrm{a}}$ & $0.1 \pm 1.1^{\mathrm{a}}$ \\
\hline
\end{tabular}

Values with different superscript letters in the same column are significantly different $(\mathrm{p}<0.05)$.

\section{Conclusions}

Thermal treatment associated with drying reduces antiradical capability of blueberry pomace, mainly by reducing total phenol and anthocyanin content. Mechanical damage induced by grinding operation of dried pomace reduces total fiber content determining water and oil interaction properties. This effect results in a lower wettability, swelling capacity, water holding and water retention capacity of fine powder. Although emulsifying activity is not affected by particle size, the emulsion stability is significantly higher in coarse powder.

\section{Acknowledgements}

Authors thank the predoctoral contract of the Universitat Politècnica de València.

\section{References}

[1] Mirabella, N.; Castellani, V.; Sala, S. Current options for the valorization of food manufacturing waste: a review. Journal of Clean Production 2014, 65: 28-41.

[2] Neacsu, M.; Vaughan, N.; Raikos, V.; Multari, S.; Duncan, G.J.; Duthie, G.G.; Russell, W.R. Phytochemical profile of commercially available food plant powders: their potential role in healthier food reformulations. Food Chemistry 2015, 179: 159-169.

[3] Cho, M.J.; Howard, L.R.; Prior, R.L.; Clark, J.R. Flavonoid glycosides and antioxidant capacity of various blackberry, blueberry and red grape genotypes determined by high-performance liquid chromatography/mass spectrometry. Journal of the Scienceof Food and Agriculture 2004, 84(13): 1771-1782.

[4] Amaya-Cruz, D.M.; Rodríguez-González, S.; Pérez-Ramírez, I.F.; Loarca-Piña, G.; AmayaLlano, S.; Gallegos-Corona, M.A.; Reynoso-Camacho, R. Juice by-products as a source of dietary fibre and antioxidants and their effect on hepatic steatosis. Journal of Functional Foods 2015, 17: 93-102.

[5] Quek, S.Y.; Chok, N.K.; Swedlund, P. The physicochemical properties of spray-dried watermelon powders. Chemical Engineering and Processing: Process Intensification 2007, 46(5): 386-392.

[6] Castagnini, J.M.; Betoret, N.; Betoret, E.; Fito, P. Vacuum impregnation and air drying temperature effect on individual anthocyanins and antiradical capacity of blueberry juice included 
into an apple matrix. LWT-Food Science and Technology 2015, 64(2): 1289-1296.

[7] AOAC Official Method 934.06 Moisture in Dried Fruits.

[8] Mertens, D.R. Gravimetric determination of amylase-treated neutral detergent fibre in feeds with refluxing beakers or crucibles: collaborative study. Journal of AOAC International 2002, 85: 1217-1240.

[9] Seguí, L.; Calabuig-Jiménez, L.; Betoret, N.; Fito, P. Physicochemical and antioxidant properties of non- refined sugarcane alternatives to white sugar. International Journal of Food Science and Technology 2015, 50(12): 2579-2588.

[10] Lee, J.; Durst, R.W; Wrolstad, R.E. Determination of total monomeric anthocyanin pigment content of fruit juices, beverages, natural colorants, and wines by the $\mathrm{pH}$ differential method: collaborative study. Journal of AOAC International 2005, 88(5): 1269-1278.

[11] Garau, M. C.; Simal, S.; Rosselló, C.; Femenia, A. Effect of air-drying temperature on physicochemical properties of dietary fibre and antioxidant capacity of orange (Citrus aurantium v. Canoneta) by-products. Food Chemistry 2007, 104(3): 1014-1024.

[12] Yasumatsu, K.; Sawada, K.; Maritaka, S.; Mikasi, M.; Toda, J.; Wada, T.; Ishi, K. Whipping and emulsifying properties of soybean products. Agricultural and Biological Chemistry 1972, 36(5): 719-727.

[13] Elleuch, M.; Bedigian, D.; Roiseux, O.; Besbes, S.; Blecker, C.; Attia, H. Dietary fibre and fibrerich by-products of food processing: Characterisation, technological functionality and commercial applications: A review. Food Chemistry 2011, 124(2): 411-421.

[14] Fuentes-Alventosa, J.M.; Rodríguez-Gutiérrez, G.; Jaramillo-Carmona, S.; Espejo-Calvo, J.A.; Rodríguez-Arcos, R.; Fernández-Bolaños, J.; Guillén-Bejarano, R.; Jiménez-Araujo, A. Effect of extraction method on chemical composition and functional characteristics of high dietary fibre powders obtained from asparagus by-products. Food Chemistry 2009, 113(2): 665-671.

[15] Wu-Ng, Y.; Benlloch-Tinoco, M.; García-Martínez, E.; Martínez-Navarrete, N. Impacto de la adición de carboximetilcelulosa en la calidad de kiwi en polvo obtenido por liofilización y atomización. Trabajo de final del Máster en Ciencia e Ingeniería de los Alimentos de la Universitat Politècnica de València 2013.

[16] Forny, L.; Marabi, A.; Palzer, S. Wetting, disintegration and dissolution of agglomerated water soluble powders. Powder Technology 2011, 206(1): 72-78.

[17] López, G.; Ros, G.; Rincón, F.; Periago, M.J.; Martínez, M.C.; Ortuno, J. Relationship between physical and hydration properties of soluble and insoluble fiber of artichoke. Journal of Agriculture and Food Chemistry 1996, 44: 2773-2778.

[18] Martínez-Las Heras, R.; Landines, E.F.; Heredia, A.; Castelló, M.L.; Andrés, A. Influence of drying process and particle size of persimmon fibre on its physicochemical, antioxidant, hydration and emulsifying properties. Journal of Food Science and Technology 2017, 54(9): 2902-2912.

[19] Zoric, Z.; Dragovic-Uzelac, V.; Pedisic, S.; Kurtanjek, Z.; Garofulic, I.E. Kinetics of the degradation of anthocyanins, phenolic acids and flavonols during heat treatments of freeze-dried sour cherry Marasca paste. Food Technology and Biotechnology 2014, 52(1): 101-108. 